\title{
A RARE CASE: NON-RECURRENT LARYNGEAL NERVE
}

\section{Mehmet Ulusahin ${ }^{1}$, Kadir Tomas ${ }^{2}$, Mithat Kerim Arslan³,}

${ }^{1}$ Idil State Hospital, General Surgery Clinic, Şırnak, Turkey

2 Recep Tayyip Erdoğan University, Training and Research Hospital, General Surgery Clinic, Rize, Turkey

${ }^{3}$ Erzincan Binali Yıldırım University, Faculty of Medicine, Department of General Surgery, Erzincan, Turkey

\author{
Address for Correspondence: Mehmet Ulusahin, E-mail: ulusahinmehmet@hotmail.com \\ Received: 11.01.2021; Accepted: 20.08.2021; Available Online Date: 20.09.2021 \\ (C) Copyright 2021 by Dokuz Eylül University, Institute of Health Sciences - Available online at https://dergipark.org.tr/en/pub/jbachs
}

Cite this article as: Ulusahin M, Tomas K, Arslan MK. A rare case: Non-recurrent laryngeal nerve. J Basic Clin Health Sci 2021; 3: 218- 220.

\begin{abstract}
Non-recurrent inferior laryngeal nerve (NRLN) is a very rare nerve variation seen during thyroidectomy. Identification and preservation of this nerve is crucial for post-operative life of the patient. In this paper, we presented a 55-year old female patient with right NRLN identified during operation performed due to multinodular goiter (MNG). This presented case was intraoperatively identified as NRLN during right lobe dissection and it was preserved through its course until entrance to the larynx with careful dissection. Patient was discharged at first postoperative day without problem during postoperative monitoring. Anatomic variations may cause nerve damage; therefore identification and preservation with careful dissection have utmost importance.
\end{abstract}

Keywords: Inferior, Non-recurrent, Laryngeal nerve, Thyroidectomy, Nerve exploration

\section{INTRODUCTION}

Non-recurrent inferior laryngeal nerve (NRLN) is a very rare variation observed during thyroid surgery (1). It has been firstly described at 1823 on cadavers and mentioned in anatomy books (1). This quite rare variation is generally identified on the right side (2-7). Cases reported on the left side are extremely rare and are generally seen in cases with situs inversus abnormality (6). It is classified into 3 types according to the course of NRLN through the entrance to the larynx (7). Type 1 non-recurrent nerve emerges immediately from the cervical vagus and runs in conjunction with the superior thyroid peduncle vessels (7). A transverse course parallel to and over the trunk of the inferior thyroid artery follows a type $2 \mathrm{~A}$ non-recurrent nerve (7). A transverse direction parallel to and under the trunk or between the branches of the inferior thyroid artery is accompanied by the type 2B nonrecurrent nerve (7). NRLN incidence among general population is below $0.5 \%$ $(3,6,7)$. Intraoperative identification of this variation and preservation of the nerve are very important for patient.

\section{CASE REPORT}

A 55-year old female patient admitted to general surgery outpatient clinic due to palpable swelling on the neck. There was no other complaint. There was a nodule sized $2.5 \mathrm{~cm}$ on left side of the neck in physical examination. Laboratory tests were normal. Hypoechoic multiple nodules whose largest ones were sized $29 \mathrm{~mm}$ in the left side and $9 \mathrm{~mm}$ in the right side were observed in cervical ultrasonographic examination; however, no significant lymph node was observed. Therefore, total thyroidectomy was suggested to the patient. Routine nerve dissection was performed on both sides during operation. Recurrent inferior laryngeal nerve (RLN) was observed on left side. However, it was not observed on right side during dissection performed near inferior thyroid artery (ITA). NRLN consistent with type 2A which courses through Berry ligament after exiting 
from carotid sheath was identified (Figure 1). Nerve was completely isolated and preserved while dissection was carefully continued. Zuckerkandl's tubercle was not identified in the patient. Patient was discharged at first postoperative day without complication. Pathology was reported a multinodular goiter. Written consent was obtained from patient.

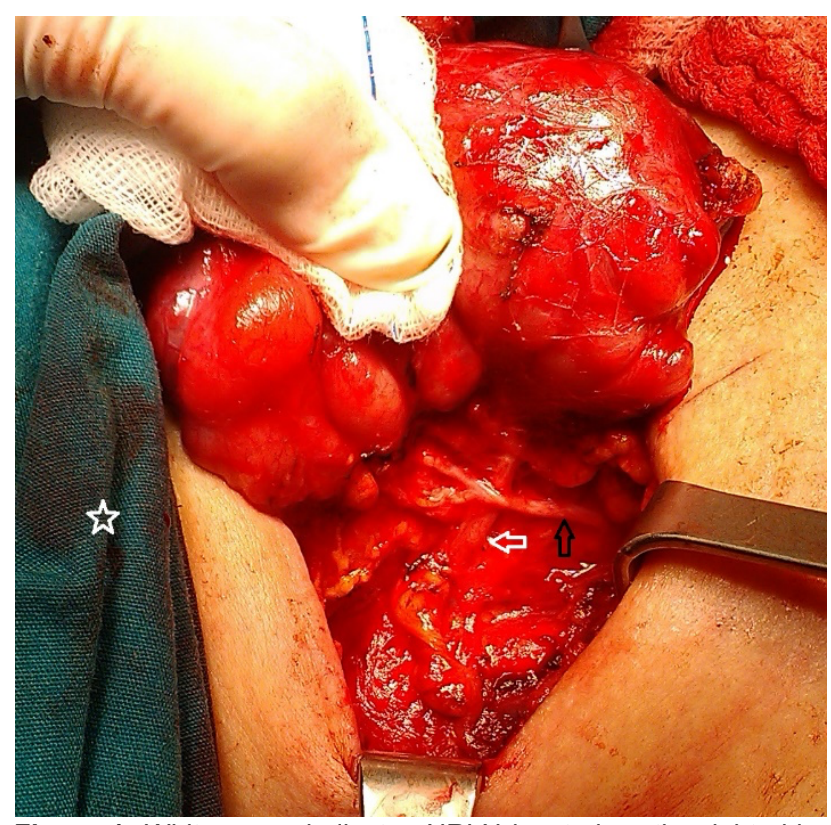

Figure 1: White arrow indicates NRLN located on the right side. Black arrow indicates ITA, star sign indicates cranial direction. (NRLN: Non-recurrent inferior laryngeal nerve; ITA: inferior thyroid artery)

\section{DISCUSSION}

Nowadays, thyroidectomy is frequently performed by many surgeons and it has been known as a safe operation. However, rarely seen complications may make intraoperative and postoperative periods very problematic. Nerve injury, vessel injury and adjacent organ injury are primary complications which may occur during thyroidectomy operations. Operating surgeon's lack of experience, wrong dissection, used surgical equipments, adhesions in the operated area due to previous surgeries may cause nerve damage: however, variable course of RLN and presence of anatomic variations may also be the reason.

Right and left ones of the both nerves originated from the vagus courses through upward and enters to tracheoesophageal groove after turning around of right subclavian artery and after turning around ligamentum arteriosum and aorta; respectively. RLNs of both sides cross ITA at the middle part of thyroid gland after continuing to course through upward. In this case of crossing, RLN may be in front of or behind the artery or among its branches as identified in many studies with different rates related with this variability $(8,9)$. Although RLNs of both sides generally course through tracheoesophageal groove, it was also reported that some of them course through paratracheal areae (in front of the groove) whereas a lower portion of them course through paraesophageal area (behind the groove) (8). Variations of RLN which RLN gives two or three branches originated before entering to larynx have been described. Although these branchings are rare, they are generally more common on the right side (8). Another anatomic variation which is quite rarely seen like the variation of patient presented in this paper is NRLN. NRLN is also more common on the right side like other anatomic variations.

In NRLN cases, right subclavian artery arises from descendant aorta and passes behind oesophagus. This abnormality is generally asymptomatic, but it may rarely causes dysphagia. There have been studies reporting that subclavian artery with retroesophageal coure can be identified with barium esophagography, endoscopy, computerized tomography and angiography performed in patients with dysphagia complaint $(6,7,10)$. Preoperative ultrasonographic has been used for diagnosis of vessel abnormality and it has been found beneficial with high success rates (11). Although preoperative identification of vessel abnormality with many modalities has been reported, they have not become a part of routine practice due to generally asymptomatic nature of this patient group and high numbers of thyroidectomy operations. Most effective method for identifying this variation is appropriate intraoperative nerve dissection like performed in our presented case. Most of the nerve injuries occur at the entrance point of the nerve to larynx. Therefore, nerve dissection must be started from below and be proceeded through upward. Like we performed in our patient, dissection is generally started at the point of crossing with ITA and nerve is explored. If it is not there, dissection is proceeded through upward and nerve is explored after careful dissection through around of Berry ligament and entrance point of nerve to larynx. NRLN may cannot be found with standard nerve dissection in some cases. In these cases, NRLN may be found when dissection is carefully proceeded from carotid sheath to medial like we performed in our presented case. 
Many authors have reported that anatomic structure named as Zuckerkandl's tubercle which is described as posteriorly located at the level of Berry ligament in lateral lobes of thyroid glands is beneficial for identification of NRLN $(2,12)$.

It has been reported that utilization of intraoperative nerve monitorization is beneficial for NRLN identification and reduces the rate of nerve injury (13). Although it has been increasingly used, it has still not been routinely used due to cost problems.

Routine nerve dissection had been previously mentioned in surgery books as an inappropriate and false approach which must be avoided. However; rates of nerve injury had been found lower in cases operated with nerve dissection in time and then nerve dissection has been started to be suggested as a standard.

\section{CONCLUSION}

RLN injury is the most frightening complication in thyroid surgery. One reason of this nerve injury may be rarely seen anatomic variations like non-recurrent nerve. No anatomic model must be considered as standard during thyroid surgery; and presence of many anatomic variations affecting nerves, vessels and their locations according to each other must be known. Crucial importance of having comprehensive knowledge about these variations and intraoperative exploration of these anatomic structures with adequate dissection for patient must be always kept in mind.

Acknowledgement: This study was presented as poster in 21th the National Surgery Congress on April 11-15, 2018 in Antalya, Turkey.

Conflict of Interest: All contributing authors declare that they have no conflicts of interest.

Informed Consent: Written informed consent was obtained from the patient who participated in this case.

Financial Disclosure: The authors declared that this study has received no financial support.

\section{REFERENCES}

1. Mra Z, Wax MK. Nonrecurrent laryngeal nerves: anatomic considerations during thyroid and parathyroid surgery. Am J Otolaryngol 1999; 20(2): 91-5.

2. Gurleyik E, Dogan S, Gunal O,Pehlivan M. The rare coincidence: nonrecurrent laryngeal nerve pointed by a Zuckerkandl's tubercle. Case Rep
Med 2012; 2012: 143049 DOI: https://doi.org/10.1155/2012/143049.

3. Marchesi M, Biffoni M, Faloci C, Nobili Benedetti $R$, Notari $P$, Mariotti $F$, at all. The inferior nonrecurrent laryngeal nerve: a report of 7 cases observed since 1987. G Chir 1999; 21(1-2): 258.

4. Sayım NY, Gül F. Two cases of non-recurrent laryngeal nerve: routine nerve exploration in total thyroidectomy. Ulus Cerrahi Derg 2013; 29(1): 33-4

5. Yetişir $F$, Özkardeş $A B$, Dündar $H Z$, Birkan $B$, Çiftci AB, Kılıç M. Non-recurrent laryngeal nerve. Ulus Cerrahi Derg 2014; 30(2): 112-4

6. Henry JF, Audiffret J, Denizot, Plan M. The nonrecurrent inferior laryngeal nerve: review of 33 cases, including two on the left side. Surgery 1988; 104(6): 977-84.

7. Toniato A, Mazzarotto R, Piotto A, Bernante P, Pagetta C, Pelizzo MR. Identification of the nonrecurrent laryngeal nerve during thyroid surgery: 20-year experience. World J Surg 2004; 28(7): 659-61.

8. Skandalakis JE, Skandalakis PN, Skandalakis LJ. Cerrahi anatomive teknik. İkinci baskı, İstanbul, Nobel Tıp Kitapevi 2000.

9. Ardito G, Revelli L, D'Alatri L, Lerro V, Guidi ML, Ardito F. Revisited anatomy of the recurrent laryngeal nerves. Am J Surg 2004; 187(2): 24953.

10. Iorgulescu R, Bistriceanu I, Badanoiu D, Calin C, Capatana $\mathrm{C}$, lordache N. Non-recurrent inferior laryngeal nerve: case report and review of the literature. J Med Life 2014; 7(4): 90-4

11. Yetisir F, Salman AE, Çiftçi B, Teber A, Kiliç M. Efficacy of ultrasonography in identification of non-recurrent laryngeal nerve. Int J Surg 2012; 10(9): 506-9.

12. Pelizzo MR, Toniato A, Gemo G. Zuckerkandl's tuberculum: an arrow pointing to the recurrent laryngeal nerve (constant anatomical landmark). J Am Coll Surg 1998; 187(3): 333-6.

13. Donatini G, Carnaille B, Dionigi G. Increased detection of non-recurrent inferior laryngeal nerve (NRLN) during thyroid surgery using systematic intraoperative neuromonitoring (IONM). World J Surg 2013; 37(1): 91-3.

14. Jatzko GR, Lisborg PH, Müller MG, Wette VM. Recurrent nerve palsy after thyroid operations-principal nerve identification and a literature review. Surgery 1994; 115(2): 139-44. 